\title{
Myocarditis mimicking acute myocardial infarction: role of endomyocardial biopsy in the differential diagnosis
}

\author{
A Angelini, V Calzolari, F Calabrese, G M Boffa, F Maddalena, R Chioin, G Thiene
}

\begin{abstract}
Objective-To test the hypothesis, using endomyocardial biopsies, that unexplained cases of apparent acute myocardial infarction were caused by myocarditis.

Material-Between 1992 and 1998, 12 patients were admitted to the coronary care unit with severe chest pain, ST segment elevation, increased serum creatine kinase and MB isoenzyme, and with wall motion abnormalities on echocardiogram highly suggestive of acute myocardial infarction. These patients were further investigated by endomyocardial biopsy, as their coronary angiograms were normal. A diagnosis of myocarditis was made according to the Dallas criteria. A panel of antibodies was used for immunohistochemical characterisation of inflammatory cell infiltrate. Polymerase chain reaction (PCR) was used to detect viral genomes in seven cases.

Results-Haematoxylin and eosin staining of the endomyocardial biopsy showed active myocarditis in six patients and borderline myocarditis in one. Immunohistochemistry was positive for inflammatory cell infiltrates in 11 patients, including all the seven who were positive on haematoxylin and eosin staining according to the Dallas criteria. Only one patient had no evidence of inflammation. PCR was positive in two patients, both for Epstein-Barr virus. Follow up showed complete resolution of echocardiographic abnormalities in all patients except one.

Conclusions-Myocarditis can mimic acute myocardial infarction in patients with angiographically normal coronary arteries, leading to errors of treatment. In patients with apparent myocardial infarction and a normal coronary angiogram, endomyocardial biopsy may help in the diagnosis of myocarditis. The sensitivity of endomyocardial biopsy was enhanced by using immunohistochemical and molecular biological techniques.

(Heart 2000;84:245-250)
\end{abstract}

Keywords: acute myocardial infarction; endomyocardial biopsy; myocarditis

It is not rare to find that patients admitted to an intensive care unit with chest pain, localised ischaemic ECG abnormalities or pathological Q waves, segmental left ventricular dysfunction on echocardiographic or cineangiographic evaluation, and mild elevation of creatine kinase have normal coronary arteries. The diagnosis in these patients is difficult as they may not have an acute coronary syndrome. Myocarditis needs to be kept in mind when considering the differential diagnosis.

Unfortunately, the clinical diagnosis of myocarditis remains a challenge owing to the nonspecific pattern of the clinical presentation and the lack of universally accepted and standardised diagnostic criteria. As the spectrum of clinical presentation is broad-including asymptomatic ECG abnormalities reported during enterovirus epidemics, vague symptoms of flu-like syndrome, congestive heart failure of recent onset, cardiogenic shock, and sudden death - many false positive and false negative clinical diagnoses may be expected. ${ }^{12}$ Endomyocardial biopsy, ${ }^{3}$ despite its low sensitivity because of frequent sampling errors and the lack of quantitative diagnostic criteria, ${ }^{4-7}$ remains the best way to diagnose myocarditis. Recent papers showed that myocarditis can masquerade as acute myocardial infarction. ${ }^{8-13}$

Our aim in this study was to define the role and diagnostic accuracy of endomyocardial biopsy in detecting myocardial inflammation compatible with myocarditis in patients with chest pain and a normal coronary angiogram; we investigated whether immunohistochemical characterisation of inflammatory cells and molecular biological techniques could increase the sensitivity of the procedure.

\section{Methods}

From January 1992 to 1998 , we studied 12 patients admitted to the coronary care unit of Padua University with severe chest pain, ECG abnormalities, and an increase in serum creatine kinase and MB fraction suggestive of acute myocardial infarction, but who had normal coronary arteries on angiography. These patients then underwent endomyocardial biopsy to confirm the clinical diagnosis of myocarditis.

CLINICAL AND HAEMODYNAMIC STUDY

The medical records of the 12 patients were carefully reviewed and the following clinical and haemodynamic data collected: age, sex, presence of cardiovascular risk factors, prodromal symptoms, ECG findings, echocardiograms on admission and on discharge, serum creatine kinase and $\mathrm{MB}$ fraction isoenzyme concentrations, serology, treatment, and follow up.

Diagnostic right and left heart catheterisation was carried out by the standard technique. Pressure in all the chambers was measured and 
Table 1 Clinical and ECG findings

\begin{tabular}{|c|c|c|c|c|c|c|c|}
\hline Patient & Age(years)/ sex & IHD risk factors & Flu-like syndrome & ECG alterations on admission & $C K-M B(p e a k)$ & Serology Ab titres & Days in hospital \\
\hline 1 & $27 /$ male & None & Enteric & Anterior & $234 / 12$ & Neg & 22 \\
\hline 2 & $21 /$ female & None & Flu & Inferolateral & $979 / 122$ & Infl $A, B$ & 16 \\
\hline 3 & $22 /$ male & Smoking & Enteric & Inferior & $1186 / 83$ & Neg & 9 \\
\hline 4 & $26 /$ male & None & Flu & Inferior & $680 / 46$ & Neg & 7 \\
\hline 5 & $35 / \mathrm{male}$ & None & None & Anterolateral & $660 / 66$ & $\mathrm{EBV}$ & 10 \\
\hline 6 & $24 /$ female & Hormones & Fever & Inferolateral & $661 / 77$ & $\mathrm{Neg}$ & 13 \\
\hline 7 & $35 /$ male & Smoking & Fever & Lateral & $847 / 59$ & Infl A,B & 15 \\
\hline 8 & $19 /$ male & None & Flu & Inferior & $572 / 95$ & Mycopl & 10 \\
\hline 9 & $18 / \mathrm{male}$ & None & Enteric & Lateral & $2415 / 351$ & Neg & 13 \\
\hline 10 & $30 /$ male & None & Flu & Anterolateral & $774 / 20$ & Infl $A, B$ & 11 \\
\hline 11 & $37 /$ female & None & None & Lateral & $246 / 30$ & Neg & 17 \\
\hline 12 & $56 /$ female & Smoking & None & Anterior & $221 / 50$ & $\mathrm{NP}$ & 13 \\
\hline
\end{tabular}

CK- MB, creatine kinase MB isoenzyme; EBV, Epstein-Barr virus; IHD, ischaemic heart disease; Infl A,B: influenza A, B virus; Mycopl, Mycoplasma pneumoniae; Neg, negative; NP, not performed.

the cardiac output determined by the Fick principle. Left ventricular end diastolic volume and ejection fraction were also calculated. Selective coronary angiography and right ventricular endomyocardial biopsy were performed.

ENDOMYOCARDIAL BIOPSY

Five biopsy specimens from the right side of the interventricular septum were obtained in each patient with a disposable Cordis bioptome, using the long sheath technique and the femoral vein approach. In four patients a sample of frozen tissue was also available. Fixation was performed with microwave assistance.

Paraffin embedded serial sections $4 \mu \mathrm{m}$ thick were cut and routinely stained with haematoxy-

\section{A}
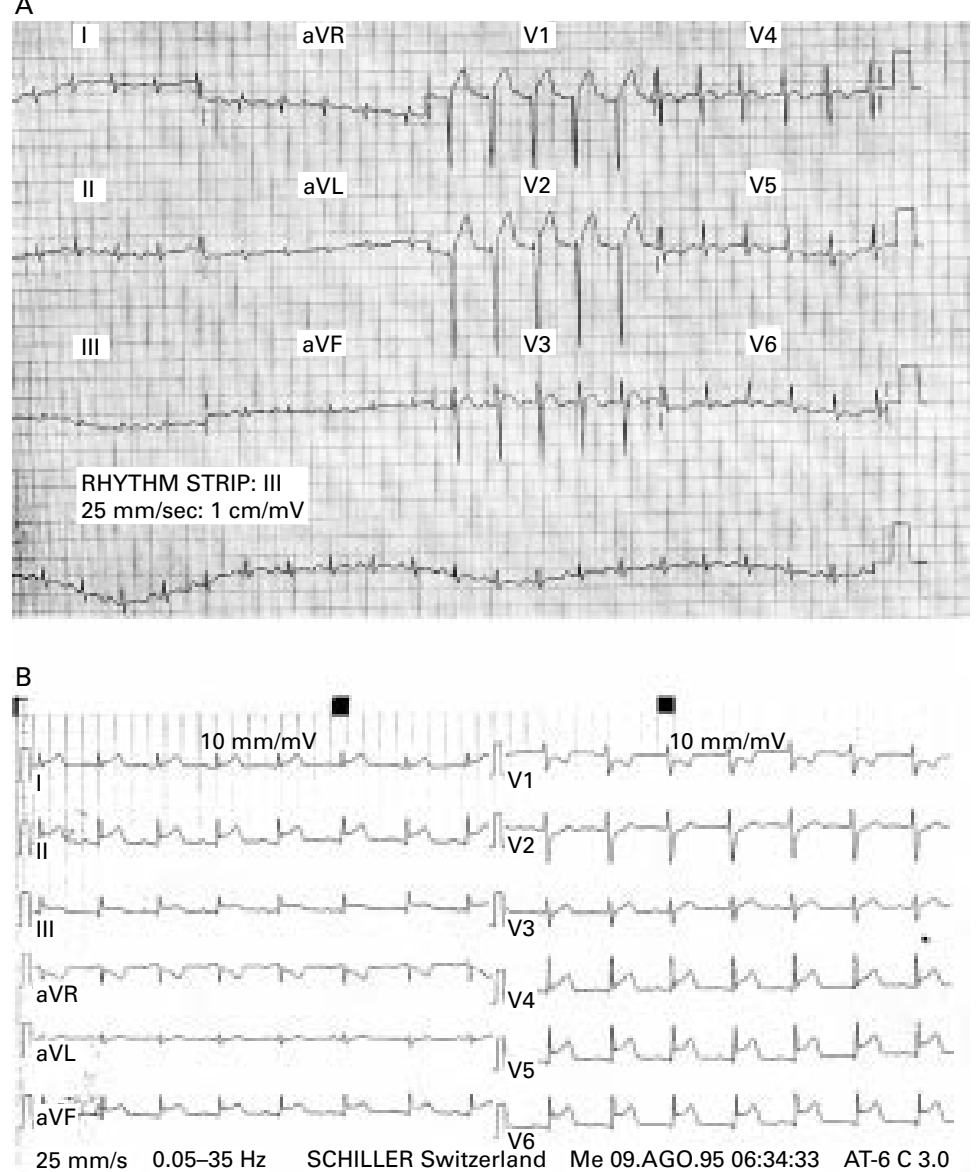

Figure 1 ECG traces on admission for patient $1(A)$ and patient $6(B)$. Note the ST segment elevation. lin and eosin, trichrome Heidenhein, and periodic acid Schiff (PAS) stains. The Dallas criteria were used to diagnose the presence of myocarditis. ${ }^{4}$

In all the samples immunohistochemistry for the characterisation of inflammatory infiltrate was carried out using the following antibodies ${ }^{14}$ : CD45 (Dako 1:20), CD43 (Dako 1:40), CD45RO (Dako 1:100), CD20 (Dako 1:100), CD68 (Dako 1:50), factor VIII (Dako 1:200), and anticytomegalovirus (Dako 1:50). The positivity of the antigen-antibody reaction was demonstrated using the avidin-biotinperoxidase complex method. Sections of formalin fixed lymph nodes served as a positive control. Immunohistochemically stained lymphocytes were independently evaluated by two pathologists. Patients with on average at least 2.5 lymphocytes/high power field $(400 \times$ magnification) in the 10 fields counted were considered to have an inflammatory infiltration..$^{15} 16$

Molecular analysis by polymerase chain reaction (PCR) was carried out in seven of the 12 patients to detect enterovirus, adenovirus, Epstein-Barr virus (EBV), cytomegalovirus, and influenza virus $\mathrm{A}$ and $\mathrm{B}$. Total RNA and genomic/viral DNA were isolated simultaneously from fresh frozen or formalin fixed myocardial specimens using Tris saturated phenol ( $\mathrm{pH}$ 6.6) RNAzol solution, as previously described. ${ }^{17}$ The quality of the nucleic acid extraction was determined using glyceraldehyde-3-phosphate dehydrogenase primers for $\mathrm{RNA}^{18}$ and $\beta$ globin primers for DNA. ${ }^{19}$ To evaluate the presence of the above mentioned viruses in the endomyocardial biopsies, PCR and reverse transcriptase (RT)-

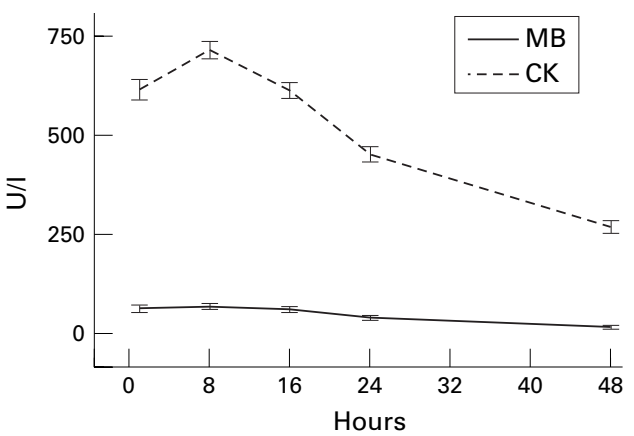

Figure 2 Time course of elevation of cardiac enzymes (creatine kinase (CK) and $M B$ isoenzyme fraction). Values are expressed as means, error bars $=S E M$. 
Table 2 Echocardiographic findings

\begin{tabular}{|c|c|c|c|c|c|c|c|c|}
\hline \multirow[b]{2}{*}{ Patient } & \multicolumn{4}{|c|}{ On admission } & \multicolumn{4}{|c|}{ On discharge } \\
\hline & LVEDV & $L V E F$ & Pericardium & LV alterations & LVEDV & $L V E F$ & Pericardium & LV alterations \\
\hline 1 & 90 & 40 & Mild effusion & Diffuse & 50 & 72 & Normal & None \\
\hline 2 & 60 & 73 & Echogenicity & None & 55 & 70 & Echogenicity & None \\
\hline 3 & Not avail & & & & 95 & 65 & Echogenicity & None \\
\hline 4 & Not avai & & & & 48 & 66 & Normal & None \\
\hline 5 & 63 & 56 & Echogenicity & None & 73 & 67 & Echogenicity & None \\
\hline 6 & 59 & 57 & Normal & Apex & 53 & 63 & Normal & None \\
\hline 7 & 89 & 44 & Normal & Diffuse & 56 & 48 & Normal & Septum \\
\hline 8 & Not avail & & & & 64 & 71 & Normal & None \\
\hline 9 & 105 & 45 & Echogenicity & Diffuse & 73 & 69 & Echogenicity & None \\
\hline 10 & 63 & 68 & Normal & None & 70 & 65 & Normal & None \\
\hline 11 & 68 & 34 & Mild effusion & Apex & & 68 & Echogenicity & None \\
\hline 12 & 49 & 56 & Normal & Apex & \multicolumn{4}{|c|}{ Not available } \\
\hline
\end{tabular}

LVEDV, left ventricular end diastolic volume $\left(\mathrm{ml} / \mathrm{m}^{2}\right) ; \mathrm{LVEF}$, left ventricular ejection fraction (\%); LV, left ventricle.

PCR were performed using primers and conditions previously reported. ${ }^{17} 2021$

\section{Results}

The clinical data and ECG findings are summarised in table 1 . The mean (SD) age of the patients was 29 (10) years (range 18-56 years). Four patients had a risk factor for ischaemic heart disease: smoking in three and oral contraceptive use in one. Nine patients reported an acute viral infection shortly before admission.

All the patients were admitted to hospital because of persistent typical anginal chest pain suggestive of an acute myocardial infarct. None showed signs of congestive heart failure. No pericardial friction rub was detected in any of the patients. The ECG findings on admission (fig 1) showed anterior ST segment elevation in two patients, anterolateral in two, lateral in three, inferolateral in two, and inferior in three. Peak creatine kinase and $\mathrm{MB}$ isoenzyme fraction ranged from a minimum of $234 / 12 \mathrm{U} / 1$ to a maximum of $2415 / 350 \mathrm{U} / 1$. The time course of the elevation of the cardiac enzymes showed that the peak occurred in all patients within 16 hours of hospital admission; complete normalisation of these variables was observed within 48 hours in all except the two cases (patients 2 and 9) who had the highest values on admission (fig 2). Serum titres of IgM antibodies for detecting infectious agents were significantly raised for influenza virus A and $\mathrm{B}$ in three patients, for Mycoplasma pneumoniae in one, and for EBV in one.

Echocardiographic findings on admission are given in table 2. Data were available for nine patients. Global hypokinesia of the left ventricle was present in three patients, and hypokinesia confined to the inferior apical region in a further three. In three patients no abnormalities could be detected. A decrease in left ventricular contractility (ejection fraction $<50 \%$ ) was seen in four patients, and was associated with left ventricular dilatation in only one of these. A pericardial effusion or increase in pericardial echogenicity were present in five of the nine patients investigated. By the time of discharge, left ventricular function had normalised in all but one patient, who retained a mild reduction of the ejection fraction.

Haemodynamic data are summarised in table 3. Catheterisation was performed within 11 days after admission. Left ventriculography revealed normal ventricular contraction in four patients, global hypokinesia in four, and segmental hypokinesia in four. The mean (SD) ejection fraction was 54 (8)\% (range 40-68\%), and it was less than $45 \%$ in only two patients. Left ventricular end diastolic volume ranged from 45 to $105 \mathrm{ml} / \mathrm{m}^{2}$ (mean $75(20) \mathrm{ml} / \mathrm{m}^{2}$ ), and there was evidence of mild left ventricular dilatation in three patients $\left(>90 \mathrm{ml} / \mathrm{m}^{2}\right)$. Left ventricular end diastolic pressure was $>14 \mathrm{~mm} \mathrm{Hg}$ in six patients (mean 14.9 (6.5) $\mathrm{mm} \mathrm{Hg}$, range $5-25 \mathrm{~mm} \mathrm{Hg}$ ), while mean pulmonary artery pressure was normal. Cardiac index was preserved in all the patients (mean $3.7(0.7) 1 / \mathrm{min} / \mathrm{m}^{2}$, range $2.9-4.8 \mathrm{1} / \mathrm{min} /$ $\mathrm{m}^{2}$ ). Selective coronary angiography showed normal coronary arteries in all the patients. No vasospasm was inducible in any patient. When we compared the site of ECG abnormalities with the areas of depressed contractility at ven-

Table 3 Haemodynamic findings

\begin{tabular}{|c|c|c|c|c|c|c|c|}
\hline Patient & $\begin{array}{l}E M B \\
\text { (day) }\end{array}$ & LVEDP & $P A P$ & $C I$ & $L V E D V$ & $E F$ & Hypokinesia \\
\hline 1 & 2 & 20 & 18 & 3.2 & 63 & 40 & Global \\
\hline 2 & 11 & 5 & 10 & 4.8 & 71 & 68 & Absent \\
\hline 3 & 1 & 20 & 20 & 4.1 & 98 & 44 & Global \\
\hline 4 & 0 & 12 & 15 & 3.5 & 79 & 55 & Absent \\
\hline 5 & 2 & 10 & 10 & 4.7 & 105 & 55 & Ant-lat, apex \\
\hline 6 & 2 & 20 & 11 & 4.6 & 54 & 47 & Apex \\
\hline 7 & 3 & 20 & 20 & 3.4 & 78 & 58 & Global \\
\hline 8 & 0 & 25 & 20 & 3.1 & 103 & 58 & Posterior apex \\
\hline 9 & 1 & 10 & 12 & 3.6 & 73 & 45 & Global \\
\hline 10 & 14 & 7 & 8 & 4.0 & 90 & 59 & Absent \\
\hline 11 & 8 & 20 & 8 & 2.9 & 45 & 65 & Absent \\
\hline 12 & 11 & 10 & 15 & 2.9 & 49 & 56 & Ant-lat \\
\hline
\end{tabular}

Ant-lat, anterolateral; CI, cardiac index $\left(1 / \mathrm{min} / \mathrm{m}^{2}\right) ; \mathrm{EF}$, ejection fraction (\%); EMB, endomyocardial biopsy; LVEDP, left ventricular end diastolic pressure ( $\mathrm{mm} \mathrm{Hg}$ ); LVEDV, left ventricular end diastolic volume $\left(\mathrm{ml} / \mathrm{m}^{2}\right)$; PAP, pulmonary artery pressure $(\mathrm{mm}$ $\mathrm{Hg}$ ). 
Table 4 Endomyocardial biopsy findings

\begin{tabular}{llllllllll}
\hline Patient & $\begin{array}{l}\text { Timing } \\
\text { (days) }\end{array}$ & $\begin{array}{l}\text { Dallas } \\
\text { criteria }\end{array}$ & Fibrosis & CD45 & CD20 & CD43 & CD45RO & CD68 & PCR \\
\hline 1 & 2 & ALM & No & + & - & + & + & + & NP \\
2 & 11 & Neg & + & + & - & - & - & NP \\
3 & 1 & ALM & + & + & - & + & + & + & NP \\
4 & 0 & Neg & + & - & - & - & - & + & NP \\
5 & 2 & Neg & + & + & - & + & + & + & EBV \\
6 & 2 & Neg & No & + & - & - & + & + & Neg \\
7 & 3 & ALM & + & + & - & + & - & + & Neg \\
8 & 0 & Neg & + & + & - & + & + & + & NP \\
9 & 1 & ALM & No & + & - & + & + & + & Neg \\
10 & 4 & BM & + & + & - & - & + & + & Neg \\
11 & 8 & ALM & + & + & - & + & + & + & Neg \\
12 & 11 & ALM & No & + & - & + & + & + & EBV \\
\hline
\end{tabular}

ALM, active lymphocytic myocarditis; BM, borderline myocarditis; Neg, negative; NP, not performed; PCR, polymerase chain reaction.

triculography, we found concordant results in four patients and discordant results in the remainder.

The endomyocardial biopsy findings are summarised in table 4. Active myocarditis according to the Dallas criteria was diagnosed in six patients (fig 3A) and borderline myocarditis in one. Of these patients, four had global hypokinesia on echocardiography or ventricu-
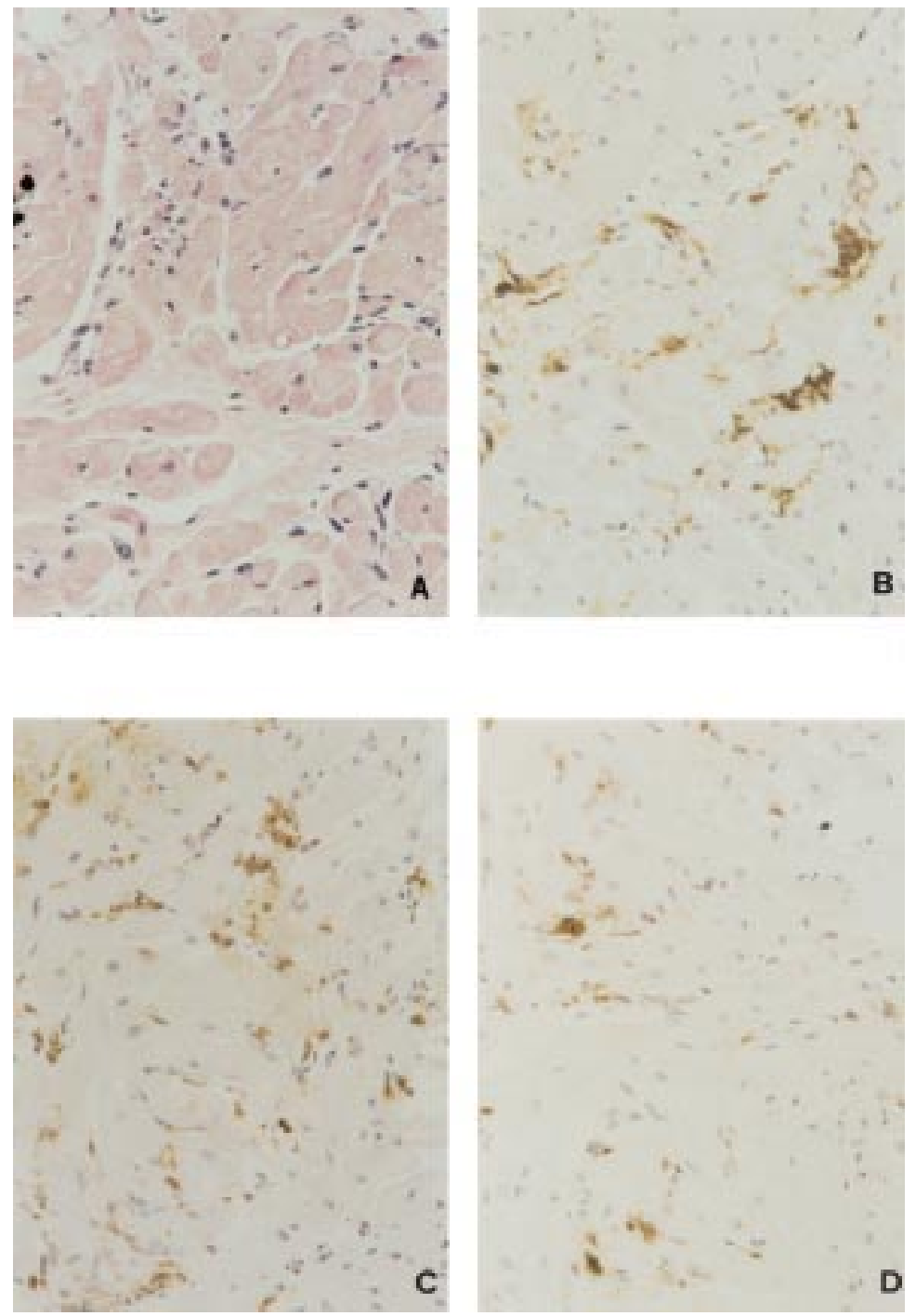

Figure 3 Patient 9: active lymphocytic myocarditis. Haematoxylin and eosin stain. (A) Inflammatory infiltrate surrounding a few necrotic myocytes. Immunohistochemical staining for CD45 (leucocytes) (B), for CD43 (lymphocytes) (C), and for CD 68 (macrophages) (D) confirmed the presence of inflammatory cells within the myocardium. lography, and two had regional hypokinesia. The ejection fraction evaluated at cardiac catheterisation did not differ significantly between patients with a positive biopsy and those with a negative biopsy, at $52.4(9.3) \%$ v $56.6(7.6) \%$. In all seven cases with a diagnosis of myocarditis according to the Dallas criteria (six active, one borderline), immunohistochemical characterisation of the inflammatory cell infiltrate revealed positivity for CD45 (common leucocyte antigen) (fig 3B), CD43 ( $\mathrm{T}$ and $\mathrm{B}$ lymphocytes) (fig 3C), CD45RO (activated $\mathrm{T}$ lymphocytes), and CD68 (monocytes/ macrophages) (fig 3D), and negative staining for CD20 (B lymphocytes). In four of the remaining five cases, which were negative according to the Dallas classification, immunohistochemistry showed the presence of an inflammatory infiltrate. Thus in only one of the 12 patients no inflammation was detectable in the myocardium.

PCR was positive for $\beta$ globin in all seven samples tested, confirming that a sufficient amount of DNA was extracted and analysed in each sample. Positive RT-PCR for glyceraldehyde-3-phosphate dehydrogenase was obtained in three of the seven samples tested. In the remaining four patients (one of whom had positive influenza virus serology), no or only weak amplicons were obtained. In two patients PCR was positive for viral genome: in both these cases EBV genome was found (fig 4); one also had an increase in EBV serum antibody titres.

Two patients received thrombolytic treatment with alteplase, intravenous heparin infusion, and glyceryl trinitrate within six hours of the onset of chest pain, without complications. Six patients received anti-inflammatory treatment afterwards: one with active lymphocytic myocarditis received corticosteroids at immunosuppressive doses for a short period; the others received indomethacin and aspirin.

Chest pain resolved within the first day. On discharge, none of the patients had $\mathrm{Q}$ waves on their ECG recordings, though ECG abnormalities persisted in the three patients who had negative $\mathrm{T}$ waves on admission. All patients were discharged in New York Heart Association functional class I within 13 (4) days.

\section{Discussion}

In this paper we evaluated retrospectively 12 consecutive patients admitted to our intensive 

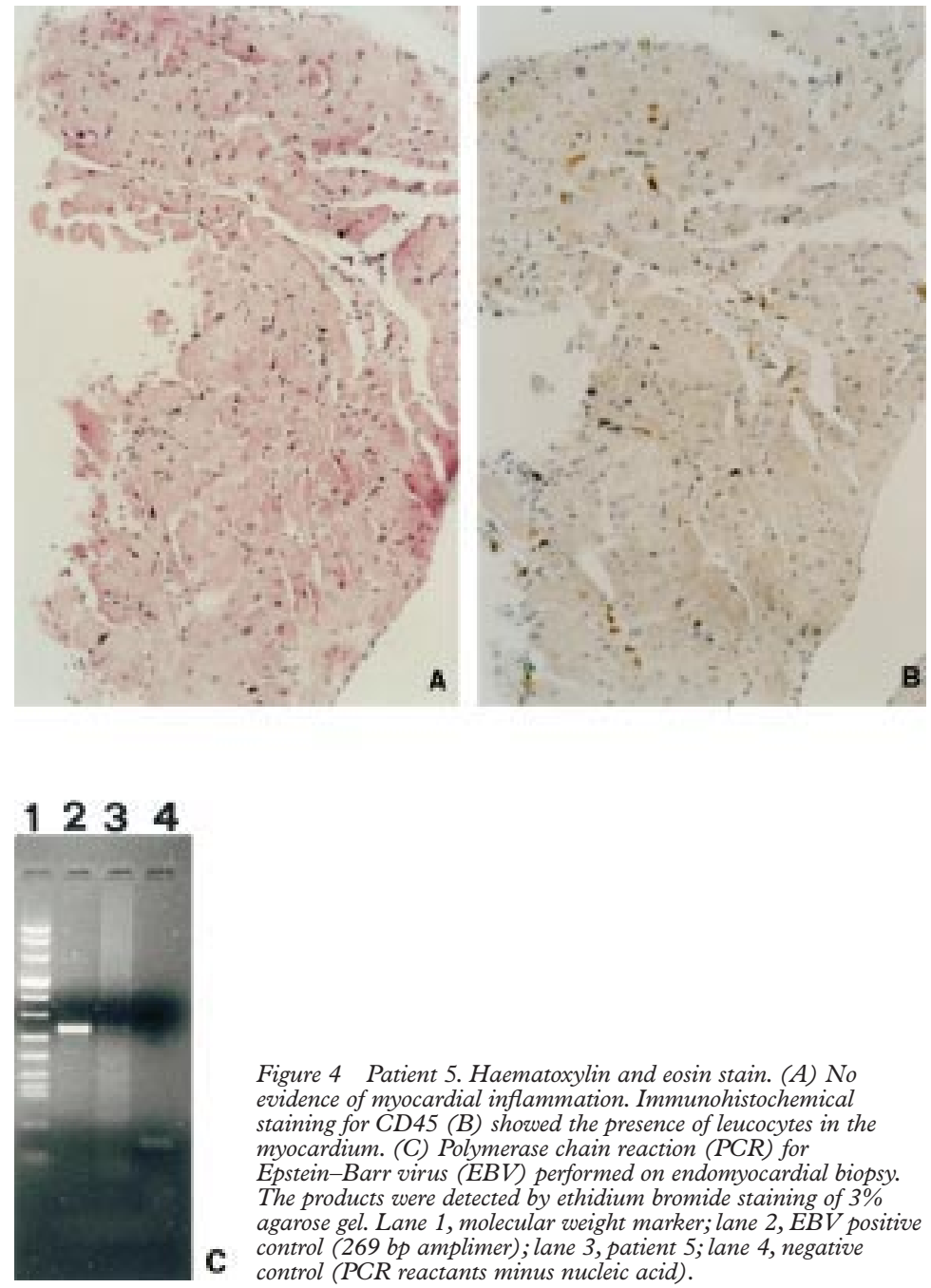

Figure 4 Patient 5. Haematoxylin and eosin stain. (A) No evidence of myocardial inflammation. Immunohistochemical staining for CD45 (B) showed the presence of leucocytes in the myocardium. (C) Polymerase chain reaction (PCR) for

Epstein-Barr virus (EBV) performed on endomyocardial biopsy. The products were detected by ethidium bromide staining of $3 \%$ agarose gel. Lane 1, molecular weight marker; lane 2, EBV positive control (269 bp amplimer); lane 3, patient 5; lane 4, negative control (PCR reactants minus nucleic acid).

care unit with chest pain, ECG abnormalities compatible with acute myocardial infarction, creatine kinase elevation, and a normal coronary angiogram, all of whom underwent endomyocardial biopsy. In such cases it is essential to consider the differential diagnosis between myocardial infarction and other causes of chest pain. Myocarditis is often neglected in this regard, but it needs to be taken into account owing to its heterogeneous presentation. It is known that such cases may mimic acute myocardial infarction in their clinical and ECG pattern. ${ }^{8-10}$ To test the hypothesis that our patients could have been suffering from myocarditis, we performed endomyocardial biopsies in all of them, using the Dallas criteria ${ }^{4}$ for evaluation. On this basis myocarditis could be detected in only seven of the 12 patients - active in six and borderline in one. The sensitivity of the Dallas criteria has often been questioned. ${ }^{7}$ Thus our next diagnostic step was to use immunohistochemical techniques to allow more sensitive detection and characterisation of inflammatory infiltrates. ${ }^{15}{ }^{1622}$ In four of the five patients who did not fulfil the Dallas criteria, immunohistochemistry showed the presence of an inflammatory infiltrate in the myocardium characterised by $\mathrm{T}$ lymphocytes and macrophages, thus excluding the possibility of acute ischaemia, which is characterised by a polymorphonuclear neutrophil infiltrate. In our study we tried to increase the diagnostic accuracy further by performing PCR for viruses ${ }^{23}{ }^{24}$ in the biopsy samples from seven of the patients. Two of these turned out to be positive for EBV. Even though EBV infection is common in the general population, cardiac involvement is infrequent and most cases follow an uncomplicated course.

Although the number of our cases was small, the detection of the EBV genome in two of them is of some interest. Previous studies have stressed the frequent non-specific ECG abnormalities found in patients with infectious mononucleosis. ${ }^{25} 26$ To our knowledge, only four cases of EBV related myocarditis have been reported so far. ${ }^{27-29}$ An aberrant immune response rather than a direct severe viral cytotoxic effect - as suggested by some investigators-could be responsible for an imbalance of inflammatory cytokines. ${ }^{20}$

We cannot exclude the possibility that the two patients with positive influenza virus serology had myocarditis caused by this virus. Unfortunately, in one of these cases PCR for RNA viruses was unsuccessful, and in the other, PCR was not performed owing to lack of adequate biopsy material. This highlights the need to obtain sufficient biopsy material at the time of the endomyocardial biopsy to investigate all the cardiotropic viruses.

The presence of an inflammatory infiltrate on immunohistochemical analysis, together with a positive PCR for myocardial virus genome, increases the diagnostic accuracy of endomyocardial biopsy in cases where the Dallas criteria would otherwise have failed to detect and characterise an inflammatory disease. Myocarditis was excluded in only one of our cases, on the basis that it was negative on both immunohistochemical and molecular analysis.

Our patients showed symptoms and ECG signs which made it necessary for the clinicians to consider the differential diagnosis between myocarditis and ischaemic heart disease. The non-specific character of the presentation was confirmed by the fact that even in the seven patients with a histological diagnosis of myocarditis based on the Dallas criteria no clinical features suggesting the correct diagnosis could be identified retrospectively. For example, the ECG abnormalities were not diffusely present in the precordial leads but were regionally distributed, even though haemodynamic studies showed global involvement of the heart.

Miklozek and colleagues reported 10 patients with acute myocarditis and apparent clinical signs of acute myocardial infarction. ${ }^{9}$ Dec and associates described 34 patients presenting symptoms of acute myocardial infarction and normal coronary arteries ${ }^{8}$; they reported a $33 \%$ incidence of myocarditis diagnosed by endomyocardial biopsy using the Dallas criteria. Both groups stressed the need for an endomyocardial biopsy in pursuing the differential diagnosis. In the recent international myocarditis treatment trial, ${ }^{30}$ only 200 of 2000 endomyocardial biopsies performed on 
the basis of the clinical diagnosis of myocarditis were positive by the Dallas criteria. In this international trial, the patients were enrolled in the study if they had had symptoms in the two previous years, while in our study the biopsy was done at a mean of 3.5 (3.9) days from the onset of symptoms. The timing of the biopsy might well influence its sensitivity. One would expect that it would be better to perform it in the early phase of the disease, at the onset of symptoms, when viral invasion produces local myocardial damage with an inflammatory response accompanied by recruitment of cytolytic $\mathrm{T}$ lymphocytes and cytokine production. In fact, Friedrich and colleagues, using contrast medium enhanced magnetic resonance, showed that acute myocarditis evolves from a focal to a disseminated process during the first two weeks after the onset of symptoms, thus potentially increasing the sensitivity of endomyocardial biopsy performed in the earlier phase of the disease. ${ }^{31}$

As clinical, angiographic, and ECG criteria are insufficient for a definitive diagnosis of myocarditis, endomyocardial biopsy is of crucial importance and may influence the clinical management of these patients. Myocarditis resulting in mild left ventricular dysfunction does not require any specific treatment, but if the diagnosis is established, the chronic inappropriate use of drugs for the management of unusual forms of ischaemic heart diseasesuch as coronary artery vasospasm or occult coronary artery disease-can be avoided. Moreover the risk of complications from the endomyocardial biopsy procedure is very low. In our centre there have been no fatal complications and only $0.06 \%$ non-fatal complications in nearly 1300 biopsies performed. Our experience indicates that a combined approach which includes assessment of the Dallas criteria, immunohistochemistry for the characterisation of the inflammatory infiltrates, and PCR for virus detection represents the new gold standard.

\section{LIMITATIONS}

This was a retrospective study carried out on a selected population, in which we evaluated only those patients admitted to the coronary care unit with suspected myocardial infarction but normal coronary angiography, who then underwent endomyocardial biopsy.

\section{CONCLUSIONS}

Myocarditis in young patients with suspected myocardial infarction and normal coronary arteries may be more common than previously thought and has a good prognosis. Endomyocardial biopsy is strongly recommended for the detection of myocarditis, and its sensitivity may be further increased by the application of immunohistochemical and molecular biological techniques. This study was supported by Regione Veneto, Venice, and
MURST, Rome, Italy. We would like to thank Dr L Cacciavillani, Dr A Ramondo, Dr R Razzolini, and Dr M Panfili for collecting the data and for stimulating discussion.
1 Dec WG, Palacios FI, Fallon JT, et al. Active myocarditis in the spectrum of acute dilated cardiomyopathies. Clinical features, histologic correlates and clinical outcome. $N$ Engl f Med 1985;312:885-90.

2 Friman G, Wesslen L, Fohlman J, et al. The epidemiology of infectious myocarditis, lymphocytic myocarditis and dilated cardiomyopathy. Eur Heart $\mathcal{F}$ 1995;16(suppl O):3641.

3 Sakakibara S, Konno S. Endomyocardial biopsy. fpn Heart $\mathcal{f}$ 1962;3:537-43

4 Aretz HT, Billingham ME, Edwards WD, et al. Myocarditis. A histopathologic definition and classification. $A m f$ Cardiovasc Pathol 1987;1:3-14.

5 Shanes JF, Ghali J, Billingham ME, et al. Interobserver variability in the interpretation of endomyocardial biopsy results. Circulation 1987;75:401-5.

6 Hauck AJ, Kearney DL, Edwards WD. Evaluation of post-mortem endomyocardial biopsy specimens from 38 patients with lymphocytic myocarditis: implications for role of sampling error. Mayo Clin Proc 1989;64:1235-45.

7 Davies MJ, DeWard DE. How can myocarditis be diagnosed and should it be treated? Br Heart f 1992;68:346-7.

8 Dec WJ, Waldman H, Southern J, et al. Viral myocarditis mimicking acute myocardial infarction. f Am Coll Cardiol 1992;20:85-9.

9 Miclozek CL, Crumpacker CS, Royal HD, et al. Myocarditis presenting as acute myocardial infarction. Am Heart $\mathcal{F}$ 1988;115:768

10 Narula J, An Khaw B, Dec GW, et al. Brief report: recognition of acute myocarditis masquerading as acute myocardial infarction. N Engl f Med 1993;328:100-4.

11 Alpert JS. Myocardial infarction in patients with angiographically normal coronary arteries. Arch Intern Med 1994;154:265-9.

12 Folger G, Eltohami EA, Hajar AH. Acute myocardialinfarction-like findings with myocarditis in infancy. Angiology 1994;45:737-41.

13 Talard P, Bouchiat C, Bonal J, et al. Les myocardites a debut pseudo-infarctoide. Ann Cardiol Angiol 1993;42:419-26.

14 Schnitt SJ, Ciano PS, Schoen FJ. Quantitation of lymphocytes in endomyocardial biopsies: use and limitations to leucocyte common antigen. Hum Pathol 1987;18:796-800.

15 Khul U, Seeberg B, Schulteiss HP, et al. Immunohistological characterization of infiltrating lymphocytes in biopsies of patients with clinically suspected dilated cardiomyopathy. Eur Heart f 1994;15(suppl C):62-7.

16 Maisch B, Hufnagel G, Schonian U, et al, for the ESETCID investigators. The European study of epidemiology and treatment of cardiac inflammatory disease (ESETCID). Eur Heart f 1995;16(suppl O): 173-5.

17 Martin AB, Webber S, Fricker FJ, et al. Acute myocarditis. Rapid diagnosis by PCR in children. Circulation 1994;90: 330-9.

18 Ercolani L, Florence B, Denaro M, et al. Isolation and complete sequence of glyceraldehyde-3-phosphate dehydrogenase gene. F Biol Chem 1988;263:1535-41.

19 Saiki RK, Scharf S, Falooma F, et al. Enzymatic amplification of beta globin genomic sequence and restriction site analysis for diagnosis of sickle cell anemia. Science 1985;230:1350-4.

20 Hebert MM, Yu C, Towbin JA, et al. Fatal Epstein Barr virus myocarditis in a child with repetitive myocarditis. Pediatr Pathol Lab Med 1995;15:805-12.

21 Claas ECJ, Sprenger MJW, Kleter GEM, et al. Type specific identification of influenza viruses $\mathrm{A}, \mathrm{B}$, and $\mathrm{C}$ by the polymerase chain reaction. $\mathcal{F}$ Virol Methods 1992;39:1-13.

22 Milei J, Bortman GFA, Grancelli H, et al. Immunohistochemical staining of lymphocytes for reliable diagnosis of myocarditis in endomyocardial biopsies. Cardiology 1990; 77:77-85.

23 Fujioka S, Koide H, Kitaura Y, et al. Molecular detection and differentiation of enteroviruses in endomyocardial biopsies and pericardial effusions from dilated cardiomyopathy and myocarditis. Am Heart f 1996;131:760-5.

24 Marti V, Coll P, Ballester M, et al. Enterovirus persistence and myocardial damage detected by 111-Indium monoclonal antimyosin antibodies in patients with dilated cardiomyopathy. Eur Heart f 1996;17:545-9.

25 Hoagland RJ. Mononucleosis and heart disease. Am 7 Med Sci 1964;248:35-40.

26 Houck GH. Involvement of the heart in infectious mononucleosis. Am F Med 1953;14:261-4

27 Frishman W, Kraus ME, Zabkar J, et al. Infectious mononucleosis and fatal myocarditis. Chest 1977;72:535-8.

28 Fish M, Barton HR. Heart involvement in infectious mononucleosis. Arch Intern Med 1958;101:636-44.

29 Jersild T. Mononucleosis infectiosa med letalt forlob. Nord Med 1942;14:1705-6.

30 Mason JW, O'Connell JB, Herskowitz A, et al. A clinical trial of immunosuppressive therapy for myocarditis. $N$ Engl $\mathcal{F}$ Med 1995;333:269-75.

31 Friedrich MG, Strohm O, Schultz-Menger J, et al. Contrast media-enhanced magnetic resonance imaging visualizes myocardial changes in the course of viral myocarditis. Circulation 1998;97:1802-9. 